\title{
A Novel Coating Method for Create Filter Media Capable to Remove Phosphate from Wastewater Effectively
}

\author{
Ali Alzeyadi' ${ }^{1}$ Nadhir Al-Ansari ${ }^{1}$, Abdulla M. Al-Rawabdeh ${ }^{2}$, Jan Laue ${ }^{1}$ \\ ${ }^{1}$ Civil, Environmental and Natural Resources Engineering, Lulea University of Technology, Lulea, Sweden \\ ${ }^{2}$ Department of Earth and Environmental Science, Yarmouk University, Irbid, Jordan \\ Email: ali.alzeyadi@ltu.se, nadhir.alansari@ltu.se, abd_rawabdeh@yu.edu.jo,jan.laue@ltu.se
}

How to cite this paper: Alzeyadi, A., Al-Ansari, N., Al-Rawabdeh, A.M. and Laue, J. (2019) A Novel Coating Method for Create Filter Media Capable to Remove Phosphate from Wastewater Effectively. Engineering, 11, 443-463.

https://doi.org/10.4236/eng.2019.118032

Received: July 20, 2019

Accepted: August 18, 2019

Published: August 21, 2019

Copyright () 2019 by author(s) and Scientific Research Publishing Inc. This work is licensed under the Creative Commons Attribution International License (CC BY 4.0).

http://creativecommons.org/licenses/by/4.0/

\begin{abstract}
Filtration materials coating with metallic oxides represented a good method for phosphate sorption. However, most of the researchers utilize chemicals as a source of metallic oxides and heating process to set the chemicals over the filtration materials. This study is aimed to introduce the furnace bottom ash FBA as a source of metallic oxides; it is available free because it is dumped as a waste material from power generation plants. The method of creating new filter media involves coating the limestone and sand by FBA, and the ordinary Portland cement OPC utilized as binder to binding the mixture materials. The water is the factor which is responsible for activating the OPC. All factors such as mixed materials ratio, water content and age of reaction have subjected to optimization process. The results revealed that the optimal mixture for phosphate removal consists of $40 \% \mathrm{FBA}, 5 \%$ OPC from dry weight of supporting material, $35 \%$ water ratio from the total weight of FBA and OPC, and 14 days are enough to complete the materials reaction. Limestone-furnace bottom ash LFBA indicated high capacity for phosphate sorption and possibility of efficiency regenerate. This study demonstrates a new method for coating the filtration materials more convenient with sustainability approach.
\end{abstract}

\section{Keywords}

Calcium-Silicate Hydrates, FBA, Metal Oxides, Sorption, Upflow Filter, Wastewater Treatment

\section{Introduction}

Phosphates have a negative effect on water quality. Water quality deteriorates in 
its presence and it cannot be used for any purpose [1]. Phosphate is significant for plants' growth in the aquatic life, but the increase of phosphate concentration in the water bodies in unacceptable level gives rise to algal bloom which lowers the levels of dissolved oxygen [2] [3]. Removing phosphate according to the conventional technologies included different approaches such as physical, chemical, biological or combination of these approaches [4] [5] [6]. However, researchers tried to develop these technologies to meet the requirements and legislations enacted by the global environmental bodies to protect the aquatic environment from nutrients.

Recently, considerable attention has been paid to the adsorption as a phosphate removal method. In comparison with other removal methods, the absorption is substantially efficient, low sludge production, economic and possibility of phosphorus removal at low concentration. Adsorption is the binding of a chemical species at a phase boundary, such as the surface of suspended particles. Various sorts of low-cost materials have been investigated to act as sorbents for phosphate such as zeolite, apatite, fly ash and red mud [7] [8] [9] [10]. Waste materials offer an attractive solution for nutrients treatment by utilizing them as a filter media [11] [12]. According to Hjelmar, Johnson [13] bottom ash is considered as one of the most dumped solid residues, thus, bottom ash is available as a free material. In this study, a new type of filter media was created. FBA is the main material, limestone or sand contributes in increasing the specific gravity of mixture and Ordinary Portland Cement OPC as a binder. The selection of FBA as phosphate sorbent is based on that the material contains $\mathrm{Fe} / \mathrm{Al}$ hydroxides or easily soluble $\mathrm{Ca} / \mathrm{Mg}$ compounds have a tendency to absorb the phosphate ions [14].

Some researchers have suggested new methodologies to enhance the efficiency of sorbents for cationic metals. Among these technologies, one is coating the ordinary sand filter by iron oxides. This composite filter media is known as Iron-oxide-coated sand IOCS. It was utilized as filter media for removal of dissolved metals and particulate matter simultaneously. IOCS was applied for removal of different metals; Benjamin, Sletten [15] have been accomplished successfully for removal of uncompleted and ammonia-complexed cationic metals $(\mathrm{Cu}, \mathrm{Cd}, \mathrm{Pb}, \mathrm{Ni}$, and Zn). While Jianbo, Liping [16] was utilized IOCS to remove the phosphate from aqueous solutions. The procedure of coating method explained in details in the paper of Benjamin, Sletten [15]. In general, a solution of $2.5 \mathrm{M} \mathrm{FeCl}_{3}$ with volume $80 \mathrm{ml}$ was poured on $200 \mathrm{ml}$ of bulk sand. Then, the mixture heated at $110^{\circ} \mathrm{C}$ and stirred for 3 hours. This is the time that the mixture looks dry. Then, the mixture exposed to temperature $550^{\circ} \mathrm{C}$ for 3 hours. Finally, the sand was cooled to the room temperature naturally in air. The coating has looked quite dark at this stage. Several authors have been prepared the IOCS according to the same process with differences in the quantities of coating chemicals, set up temperature and heating time to achieve the most efficient Iron-oxide-coated sand. The physical characteristics for filter media play a crucial role in pollutants cap- 
ture process. Consequently, some researchers concentrated their efforts to developing the physical aspects of filter media such as size, shape, surface area and porosity. Li, Cui [17] utilized clay and sodium silicate as additives and mix them with blast furnace dust BFD to create a blast furnace dust clay sodium silicate ceramic particles (BCSCP), new filter media act as a biofilm supporter. Hence, improve the filtration system efficiencies for removal of $\mathrm{COD}$ and $\mathrm{NH}_{3}-\mathrm{N}$. Calcination temperature is one of the most important factor which considered in the process of materials mixing to obtain the optimal BCSCP mixture; the researcher was applied calcination temperature $\left(500^{\circ} \mathrm{C}\right.$ to $\left.800^{\circ} \mathrm{C}\right)$. As illustrated previously, different sorts of low-cost materials have been applied as filter media to remove phosphate or other cation metals. However, the majority of methods for developing the performance of these materials as sorbents included materials heating. The heating is working as a binder factor to achieve the materials binding. The need for high temperature in the filter media preparation leads to consume high energy. Especially, when prepare large quantities for on-site wastewater treatment plants. This limitation has triggered development of alternative method in term of materials binding which consistent with the sustainability approach. In this work, the water was added with OPC as binding factor to create the binding of furnace bottom ash FBA over the surface of limestone and sand. Consequently, obtain new type of filter media contributes in enhance the filtration process efficiency for phosphate removal.

\section{Material and Method}

\subsection{Material}

FBA is the waste material that utilized in this experimental work to investigate its capability for phosphate removal. FBA was obtained from Warrington power station in North West England. Specific gravity analysis was performed as shown in Table 1, and it is noticeable that the specific gravity for FBA is 1.29. The materials with specific gravity $>1$ can be floating even under low flow rate, while material such as FBA can be floating in case of high influent flow rate. On the other hand, materials such as limestone and sand with specific gravity 2.65 and 2.57 respectively are characterized as a good filter media in term of physical characteristics.

$\mathrm{X}$-ray fluorescence spectrometer (XRF) was performed to characterization of chemical composition for FBA as shown in Table 2. FBA consist of oxides that tend to retain the $\mathrm{P}$ ions such as $\mathrm{Al}_{2} \mathrm{O}_{3}$ and $\mathrm{Fe}_{2} \mathrm{O}_{3}$. These oxides are chemically active because the original material (coal) is exposed to high temperature for power generation. While the limestone and sand are inert material. Omya UK Ltd supplied the limestone and sand for this work.

The decision of coating the FBA after grinding it over the limestone or sand was based on the examination of the chemical and physical characteristics for FBA. The new filter media is characterized by high surface area (Increase the contact chance with influent), contain $\mathrm{Al}_{2} \mathrm{O}_{3}$ and $\mathrm{Fe}_{2} \mathrm{O}_{3}$ (capable to retain $\mathrm{P}$ ) and 
Table 1. Physical characteristics of each material applied in this experimental work.

\begin{tabular}{ccccc}
\hline Parameters & Unit & FBA & Limestone & Sand \\
\hline Specific gravity S.G & & 1.29 & 2.65 & 2.57 \\
Porosity $\mathcal{E}$ & & 0.667 & 0.462 & 0.364 \\
Bulk density $\rho$ & $\mathrm{g} / \mathrm{cm}^{3}$ & 0.477 & 1.474 & 1.585 \\
Permeability K & $(\mathrm{m} / \mathrm{s})$ & 0.025 & 0.014 & 0.11 \\
d10 & $\mathrm{mm}$ & 0.677 & 0.68 & 0.432 \\
d60 & $\mathrm{mm}$ & 3.838 & 2.12 & 1.059 \\
Uniformity coefficient U.C & & 5.669 & 3.118 & 2.45 \\
Parameters & Unit & FBA & Limestone & Sand \\
\hline
\end{tabular}

Table 2. Chemical composition of FBA and OPC.

\begin{tabular}{ccccccccccc}
\hline $\begin{array}{c}\text { Chemical } \\
\text { Composition }\end{array}$ & $\mathrm{CaO}$ & $\mathrm{SiO}_{2}$ & $\mathrm{Al}_{2} \mathrm{O}_{3}$ & $\mathrm{MgO}$ & $\mathrm{Fe}_{2} \mathrm{O}_{3}$ & $\mathrm{~K}_{2} \mathrm{O}$ & $\mathrm{TiO}_{2}$ & $\mathrm{Na}_{2} \mathrm{O}$ & $\mathrm{CHO}$ & Traces \\
\hline FBA & 1.26 & 21.29 & 10.02 & 0.65 & 6.28 & 0.73 & 0.26 & 0.03 & 58.89 & 0.58 \\
OPC & 62.37 & 26.63 & 2.43 & 1.57 & 1.745 & 0.72 & 0.38 & 1.53 & - & 0.04 \\
\hline
\end{tabular}

improve the physical characteristics by coating FBA powder over limestone or sand, especially, the specific gravity. The coating process needs a binder to create a bonding between the FBA and limestone or sand. OPC is the binder which utilized in this work because it is available and easy to activate it as binder (the activation method is adding water). The chemical composition of OPC is illustrated in Table 2.

\subsection{Filter Media Preparation}

The FBA was grinding in 21 capacity grinder with pestle and mortar for $10 \mathrm{~min}$ to obtain the FBA as fine powder. The limestone and sand were washed to remove any fine particles and debris which may effect on the mixture bonding, and then dried naturally in air. The limestone-furnace bottom ash LFBA and sand-furnace bottom ash SFBA were prepared as follows: the materials (FBA, $\mathrm{OPC}$ and limestone or sand) were mixed in Hobart $5 \mathrm{l}$ capacity bench mixer as a dry mixture for $2 \mathrm{~min}$. Then water added during mixing process and kept the bench mixer mixing for $4 \mathrm{~min}$. then the mixture was left over plastic sheets for 28 days for curing. The mixture has been kept at room temperature $20^{\circ} \mathrm{C}$ and moisturized it regularly to protect it from loss of moisture. Consequently, the OPC will be built cementitious bonds between the mixed materials to gain the final product. FBA, OPC, water ratio and curing time are the factors were considered in the LFBA and SFBA preparation. The ratio of materials added depends on the quantity of limestone or sand, while the water ratio depends on the blended quantity of FBA and OPC. The mixtures were produced as one mass; a gentle crushing was applied to obtain the filter media as particles. 


\subsection{Optimization Process}

The first mixture consist of 50\% FBA and 5\% OPC from the dry weight of limestone or sand, 35\% water ratio from FBA and OPC mixture and the curing time is 28 days. The obtained mixtures (LFBA and SFBA) were subjected to series of tests such as scanning electron microscopy SEM, X-ray fluorescence XRF and column test to determine which filter media have achieved better performance. The proposed OPC ratio was based on economic perspective and to maintain the chemical characteristic of FBA. The hydration of OPC increases significantly in the presence of pozzolanic material such as FBA [18] [19]. Thus, decrease OPC ratio is important to avoid further hydration which could alter the effective properties of FBA. However, the impact of the four factors on the performance of new created media in terms of phosphate removal has been investigated. Table 3 shows the experimental conditions have applied to obtain the optimal created filter media.

Table 3. Optimization process the factors which influence on the efficiency of created mixture for phosphate sorption.

\begin{tabular}{|c|c|c|c|c|}
\hline Variables & FBA dosage \% & Binder (OPC) \% & Water ratio \% & Curing time (days) \\
\hline \multicolumn{5}{|l|}{ Test No. } \\
\hline 1 & 50 & 5 & 35 & 28 \\
\hline \multicolumn{5}{|l|}{ Water ratio } \\
\hline 2 & 50 & 5 & 25 & 28 \\
\hline 3 & 50 & 5 & 35 & 28 \\
\hline 4 & 50 & 5 & 45 & 28 \\
\hline 5 & 50 & 5 & 55 & 28 \\
\hline \multicolumn{5}{|l|}{ Binder (OPC) } \\
\hline 6 & 50 & 2.5 & $\mathrm{a}$ & 28 \\
\hline 7 & 50 & 5 & a & 28 \\
\hline 8 & 50 & 10 & a & 28 \\
\hline \multicolumn{5}{|l|}{ FBA dosage } \\
\hline 9 & 30 & $\mathrm{~b}$ & $\mathrm{a}$ & 28 \\
\hline 10 & 40 & $\mathrm{~b}$ & $\mathrm{a}$ & 28 \\
\hline 11 & 50 & $\mathrm{~b}$ & a & 28 \\
\hline \multicolumn{5}{|l|}{ Curing time } \\
\hline 12 & c & $\mathrm{b}$ & a & 7 \\
\hline 13 & c & $\mathrm{b}$ & a & 14 \\
\hline 14 & c & $\mathrm{b}$ & $\mathrm{a}$ & 28 \\
\hline
\end{tabular}

a: Selected optimum water ratio. b: Selected optimum binder dosage. c: Selected optimum FBA dosage. *The weight of limestone and sand in all the tests is $1500 \mathrm{~g}$. ${ }^{\star}$ Test 1 included two mixtures (LFBA \& SFBA) ${ }^{\star}$ Test 2 to 14 have applied for the efficient mixture from test 1 . 


\subsection{Synthetic Phosphate Solution}

According to Jenkins, Ferguson [20] the total phosphorus (TP) presented in the municipal wastewater was $10 \mathrm{mg} / \mathrm{l}$. In fact, the inorganic phosphorus (orthophosphate) is the target of this study. However, most of the organic phosphorus is decomposed to orthophosphate by bacterial action. Therefore, the concentration of the phosphate solution used in these experiments was $10 \mathrm{mg} / \mathrm{l}$. The aqueous solution of phosphate was prepared from dissolving $14.3 \mathrm{mg}$ of potassium dihydrogen orthophosphate $\left(\mathrm{KH}_{2} \mathrm{PO}_{4}\right)$ for each one litter of deionized water to obtain phosphate solution at concentration $10 \mathrm{mg} / \mathrm{l}$.

\subsection{Lab-Scale Filter}

In the present study, lab-scale filters were set up as shown in Figure 1. The filter is cylindrical shape had a diameter of $10 \mathrm{~cm}$ and height $45 \mathrm{~cm}$ and had an up-flow configuration. The filter was packed with gravel at height $10 \mathrm{~cm}$ from the bottom to maintain the influent flow smoothly. The novel filter media (LFBA and SFBA) was packed over the gravel layer for height $25 \mathrm{~cm}$. Influent was fed into the cylinder from the top centre of the filter by submersible pump placed inside the feed tank. The influent continues to flows downward through feed pipe placed inside the centre of filter media. Then the influent introduced into the bottom of the filter bed and distributed inside the novel filter media during the way out from the filter outlet at the top of the filter. Treated effluent exits through the effluent pipe to back again into the feed tank. The aqueous solution is recirculating until achieve phosphate concentration $0.1 \mathrm{mg} / \mathrm{l}$. The fed influent volume was 81 and it is pumped at flow rate $1 \mathrm{l} / \mathrm{min}$. Hence, the one cycle time is $8 \mathrm{~min}$. The flow rate $1 \mathrm{l} / \mathrm{min}$ was selected based on studies applied to understand the transfer behaviour of contaminants inside limestone and sand in lab-scale up-flow [21] [22].

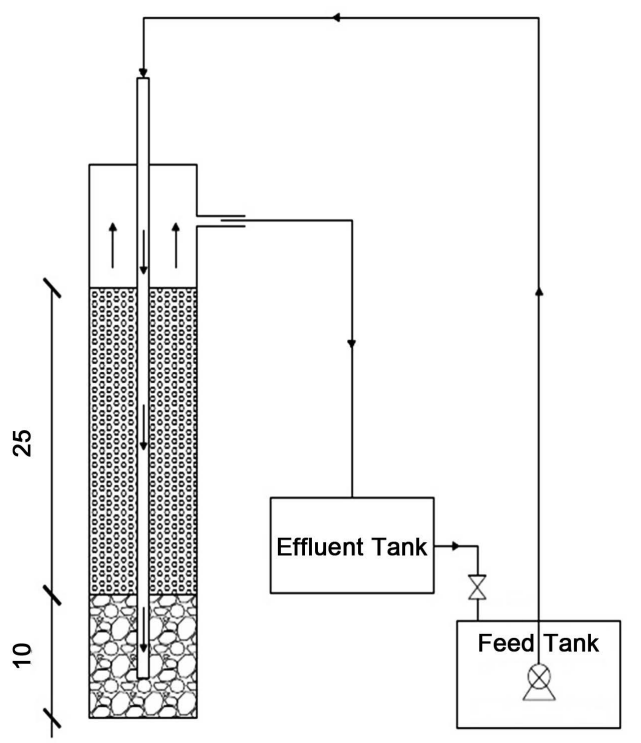

Figure 1. Schematic diagram of upflow filter set-up (dimensions unit is $\mathrm{cm}$ ). 


\subsection{Analytical Method}

Effluent samples were taken regularly, and measurements of the phosphate by HACH LANGE DR 2800 spectrophotometer, according to the Amino Acid method. The used reagents in this method (molybdate and amino acid reagent) were added to the samples in volume ratio 1:25 and the reaction period is $10 \mathrm{~min}$. The colour of samples has been converted to blue which indicate the presence of phosphate in samples. The samples colour became lighter over the course of experiment operating as illustrated in Figure 2; this is an indication of treatment. The fluctuation of $\mathrm{pH}$ slightly appears in the final effluent of wastewater treatment plants; it is remain in relatively tight band with an average of 7.5 [23]. Thus, maintaining the $\mathrm{pH}$ of phosphate solution at average 7.5 necessary to simulate the wastewater characteristics. The $\mathrm{pH}$ and temperature was monitored routinely during the experimental period.

\section{Results}

\subsection{Filter Media Characteristics}

Limestone and sand, with a particle size ranging from 1 to $2 \mathrm{~mm}$, was used as the supporting material for new filter media. The weight of limestone and sand that applied in these experiments was $1500 \mathrm{~g}$. Thus, as illustrated in Table 3 for the first test the added FBA and OPC were $750 \mathrm{~g}$ and $75 \mathrm{~g}$ respectively, and the added water was $20 \mathrm{ml}$. As a result of OPC hydration a calcium hydroxide has been released which react with FBA to produce a bonding between the mixture materials by creating a calcium-silicate hydrate (C-S-H). The availability of high amounts of calcium and silicate in the composite material lead to make the calcium-silicate hydrates (C-S-H) the predominant binder. On the other hand, the released calcium hydroxide reacts with other FBA oxides to produce hydrates depending on the amount of the oxide such as calcium-aluminate hydrates. Many researchers displayed in the presence of moisture a chemical reaction take place between the aluminium oxides and calcium hydroxide at ordinary temperature to form compounds having cementitious properties. The cementitious behaviour for FBA is beneficial to increase the bonding between the composite

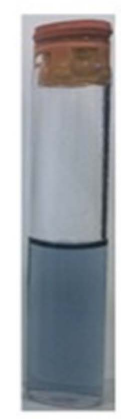

$10 \mathrm{mg} P / L$

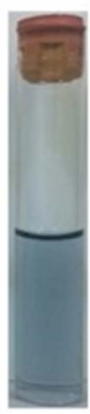

$8 \mathrm{~min}$

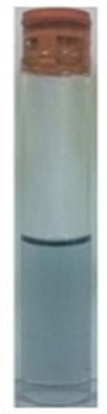

$16 \mathrm{~min}$

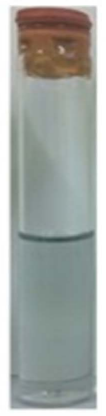

$32 \min$

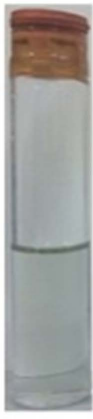

$64 \mathrm{~min}$

Figure 2. The samples colour becomes lighter over the course of experiment operating as indication of phosphate sorption (photos taken by author). 
materials but in the same time, it is reducing the availability of the $\mathrm{Al}_{2} \mathrm{O}_{3}$ and $\mathrm{Fe}_{2} \mathrm{O}_{3}$ which they are necessary to retain the phosphate during the treatment process. Table 4 shows the chemical composition for both new filter media LFBA and SFBA.

In comparison with Table 2, the amount of $\mathrm{Al}_{2} \mathrm{O}_{3}$ and $\mathrm{Fe}_{2} \mathrm{O}_{3}$ were reduced because their reaction with the calcium hydroxide that released from OPC hydration to produce cementitious compounds. It is noticeable that the reduction for $\mathrm{Al}_{2} \mathrm{O}_{3}$ more than $\mathrm{Fe}_{2} \mathrm{O}_{3}$. The amount of $\mathrm{Al}_{2} \mathrm{O}_{3}$ in $\mathrm{FBA}$ is available more than $\mathrm{Fe}_{2} \mathrm{O}_{3}$. Therefore, calcium hydroxide has better chance to react with $\mathrm{Al}_{2} \mathrm{O}_{3}$ to create hydrates.

The process of creating new filter media alters the physical and chemical characteristics for the material. SEM was applied to investigate the final morphology for the LFBA and SFBA. SEM is a good tool to analysis and observes the changes in particles surface characteristics for new filter media. The information about the surface texture which provided by SEM imaging showed that LFBA offered higher porosity and larger total surface area in comparison with SFBA. Coating process lead to distribute FBA over limestone as an agglomerated and irregularly shaped particles as shown in Figure 3(b) the bends and protrusions on the limestone surface as shown in Figure 3(a) could be provide the support to present the LFBA surface in this formation. On the other hand, the sand surface as illustrated in Figure 3(c) appears less complicated compared with limestone. Hence, the SFBA as shown in Figure 3(d) seems to be less porosity and total surface area compared with LFBA.

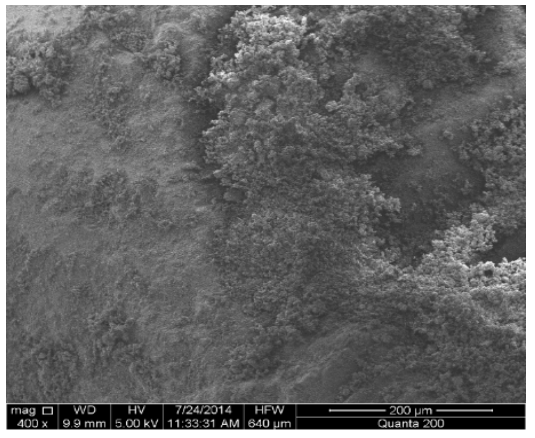

(a)

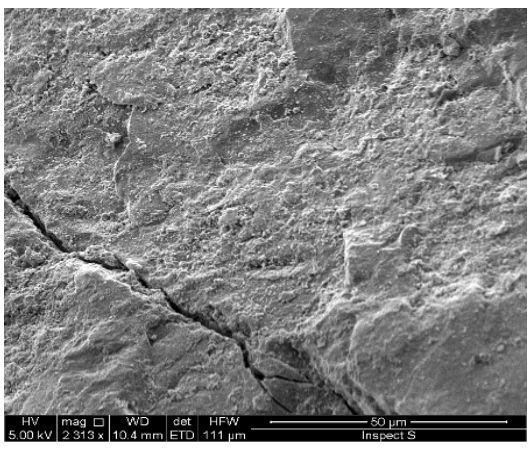

(c)

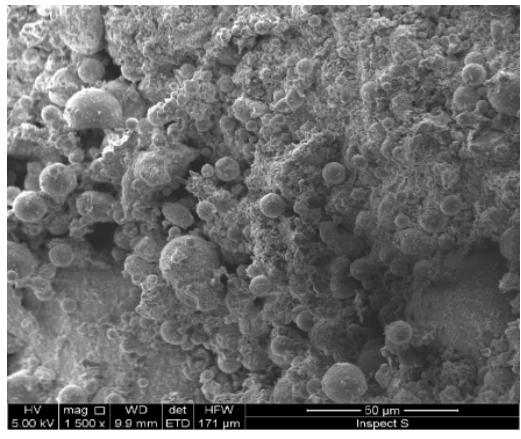

(b)

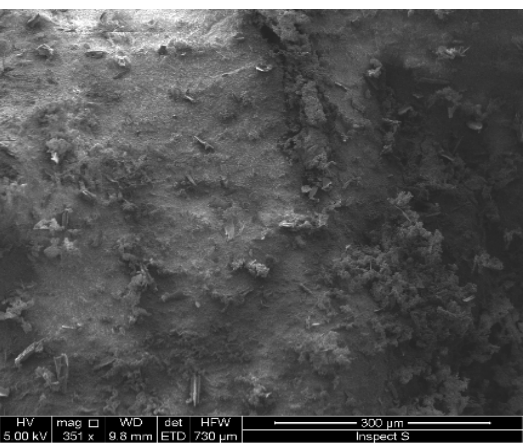

(d)

Figure 3. SEM comparison of material surface before and after coating. 
Table 4. Chemical composition for coated material.

\begin{tabular}{ccccccccccc}
\hline $\begin{array}{c}\text { Chemical } \\
\text { Composition }\end{array}$ & $\mathrm{CaO}$ & $\mathrm{SiO}_{2}$ & $\mathrm{Al}_{2} \mathrm{O}_{3}$ & $\mathrm{MgO}$ & $\mathrm{Fe}_{2} \mathrm{O}_{3}$ & $\mathrm{~K}_{2} \mathrm{O}$ & $\mathrm{TiO}_{2}$ & $\mathrm{Na}_{2} \mathrm{O}$ & $\mathrm{CHO}$ & Traces \\
\hline FBA & 6.54 & 52.78 & 5.62 & 4.27 & 5.53 & 1.79 & 0.98 & 1.13 & 20.67 & 0.71 \\
OPC & 10.47 & 34.19 & 6.52 & 4.81 & 6.05 & 1.84 & 0.97 & 1.17 & 33.36 & 0.62 \\
\hline
\end{tabular}

The physical characteristics for the filter media such as porosity, shape and surface area play a vital role in treatment process by increase the chance of influent contact with filter media. According to the SEM images, the LFBA presented better physical properties compared with SFBA. However, the importance of chemical properties could not be ignored in terms of retain the phosphate ions on filter media surface. The discussion of the feasibility of using LFBA and SFBA as filter media for phosphate removal is based on the experimental results in this present study.

\subsection{Safety Examination}

Some researchers indicate that the bottom ash and fly ash which produce from power generation plants contain several heavy metals such as $\mathrm{Pb}, \mathrm{Zn}, \mathrm{Cd}$ and $\mathrm{Cu}$. However, bottom ash is released heavy metals less than fly ash [24] [25]. Nevertheless, the fly ash and bottom ash utilized to adsorption of heavy metal contaminants in water and wastewaters [26]. According to the XRF analysing which obtained for LFBA and SFBA as shown in Table 4, the traces are consist of $\mathrm{BaO}$, $\mathrm{P}_{2} \mathrm{O}_{5}, \mathrm{SrO}, \mathrm{MnO}, \mathrm{ZrO}_{2}, \mathrm{ZnO}, \mathrm{Y}_{2} \mathrm{O}_{3}$ and $\mathrm{CuO}$. All these oxides are available with minor weight percentages. However, before embarking the study of the validity and efficiency of LFBA and SFBA for phosphate removal from wastewater treatment an inspection for materials safety was conducted. Atomic absorption spectroscopy AAS was utilized to determine the concentration of heavy metals which expected to leach from LFBA and SFBA. The results revealed that the concentration of leaching samples for heavy metals such as $\mathrm{Zn}, \mathrm{Cd}$ and $\mathrm{Cu}$ are very low and approach to zero. While the $\mathrm{Pb}$ concentration was $0.005 \mathrm{mg} / \mathrm{l}$, according to the Environmental Protection Agency EPA level for $\mathrm{Pb}$ in water delivered to users of public drinking water systems is $0.015 \mathrm{mg} / \mathrm{l}$ [27]. Consequently, LFBA and SFBA are safe to introduce as filter media for phosphate removal.

\subsection{Investigating the Filter Material Efficiency}

The laboratory made phosphate solution pumped into the upflow filtration system as shown in Figure 1. The phosphate removal rate was investigated when the LFBA is the packed media. Under same experimental conditions, the SFBA was packed in filtration system to determine which filter media presented better treatment performance. The samples have been collected during continuous flow cycles. From the obtained results for LFBA, the phosphate removal rate is about $64 \%, 97 \%$ and $100 \%$ for cycles 1,2 and 4 respectively. It is noticeable there is a drastically reduced for phosphate amount at first cycle as shown in Figure 4(a). While the removal rate became less for next cycles; after two flow cycles, 


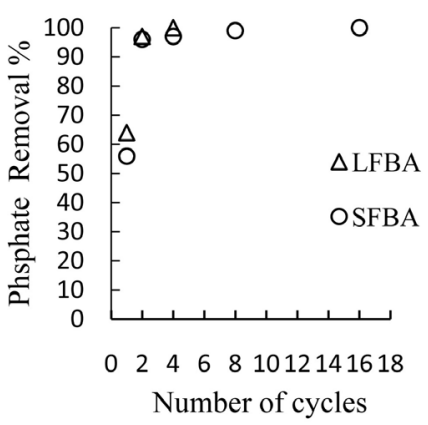

(a)

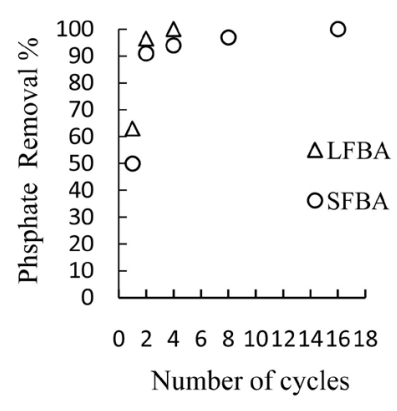

(b)

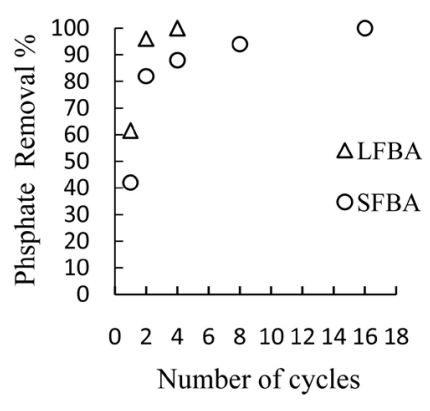

(c)

Figure 4. Phosphate removal percentage by the first created mixture for three runs. (a) First run; (b) Second run; (c) Third run.

LFBA achieved 97\% phosphate removal, and then the removal rate became slow even when increase the number of flow cycles. The phosphate removal achieved completely after the fourth cycle. On the other hand, SFBA exhibited the same phosphate removal pattern for LFBA. After one cycle, $56 \%$ from phosphate was removed and total removal was $96 \%$ after the second cycle. In comparison with the results of the first two cycles, the removal rate decreased sharply as shown in Figure 4(a). The experiment carried out for two more runs as shown in Figure 4(b) and Figure 4(c) to observe if any changes happened in the removal rate pattern. The results revealed that a large amount of phosphate was removed for both filter media during continuous feeding for short time, and then the removal rate became too much lower in the next cycles. The similarity in removal behaviour for both filter media is due to the fact that the limestone and sand surface have been coated by the same coating material FBA. Consequently, they almost have the same chemical characteristics for their surface that contribute to retain of phosphate. However, it is noticeable that the LFBA presented better phosphate removal performance in comparison to SFAB over all cycles and along all runs as illustrated in Figure 4. Additionally, LFBA has achieved the complete phosphate removal in shorter periods than SFBA. Based on the results of the XRF, the LFBA contain slightly more $\mathrm{Al}_{2} \mathrm{O}_{3}$ and $\mathrm{Fe}_{2} \mathrm{O}_{3}$ from SFBA. Moreover, according to the SEM images as shown in Figure 3 the LFBA presented better physical properties compared with SFBA. LFBA offered higher porosity and larger total surface area; it might be the physical characteristics for limestone have the positive impact to introduce the LFBA as more efficient filter media. 
Hence, the limestone is the supporting material for the rest of mixtures from test 2 to 14 as shown in Table 3 to obtain the optimum preparation conditions that reflect positively on phosphate removal.

\subsection{Obtain Optimal Filter Media}

The essential step in the process of creating the new filter media is adding a combination of chemicals such as FBA and OPC to establish a bonding between them and supporting material (limestone). The proposed chemicals quantities are responsible on the nature of the chemical and physical properties for produced media. In addition, the chemicals reaction depending on the quantity of added water and curing time. In this part of research, all factors that have key impact on the final production of filter media were subjected to an investigation to introduce the most feasible mixture which achieving better phosphate removal. As shown in Table 3, the optimization process start with water, OPC, FBA ratio and curing time respectively. The factors examination was considered in this sequence according to their influence on optimization process.

The study starts with water ratio because it is the catalyst for the additives reaction to form the final composition for LFBA. In last test regarding determine the efficiency of supporting material, the applied water ratio was $35 \%$. For the optimal water ratio, the other factors kept the same and the water ratio applied at $25 \%, 45 \%$ and $55 \%$ from the dry weight of FBA and OPC. The results that presented in Figure 5 revealed that the water ratio at $35 \%$ tend to be the optimal ratio which will depend in the following experiments. Reduction the water quantity to $25 \%$ caused a significant drop in the capability of filter media to treat the phosphate. While increasing the water amount more than 35\% leads to minor reduction in mixture removal efficiency as shown in Figure 5 for water ratio $45 \%$ and $55 \%$. The water ratio is extremely sensitive for additives reaction. Thus, the low added water quantity affect negatively on the formation of the final product characteristics.

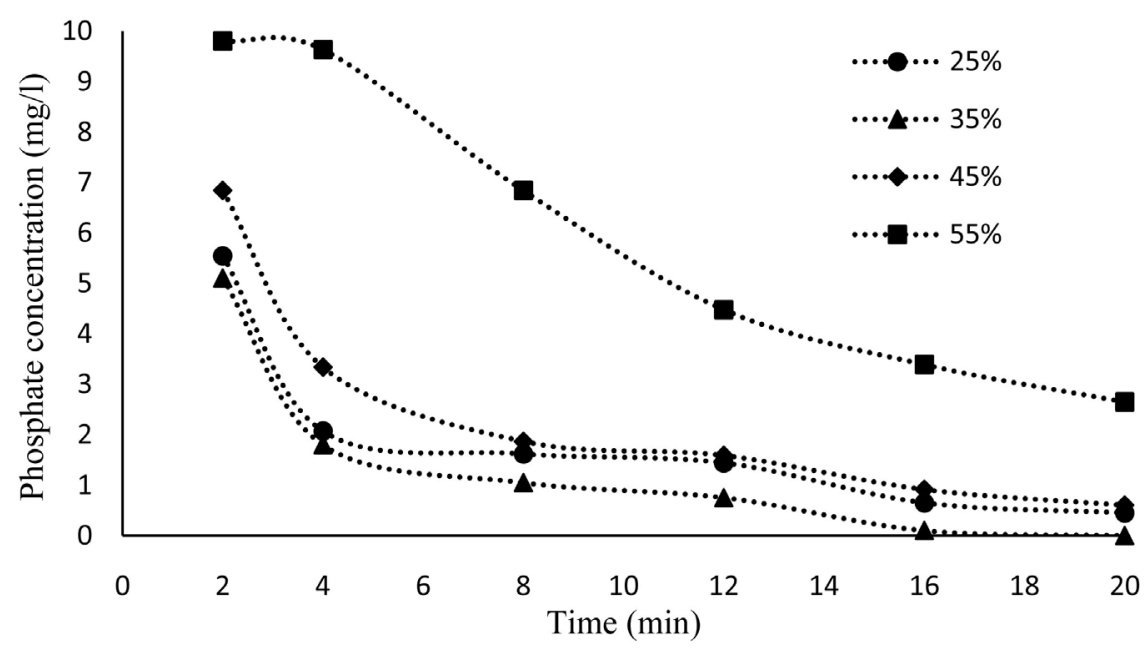

Figure 5. Effect of water ratio on the removal of phosphate. 
Increase the OPC amount in the mixture will affect positively on the strength of the materials bonding. Consequently, achieve successful coating process. On the other hand, it is affect negatively on the chemical composition of new filter media. Especially, the availability of $\mathrm{Al}_{2} \mathrm{O}_{3}$ and $\mathrm{Fe}_{2} \mathrm{O}_{3}$, which they are responsible on phosphate capture from the influent. The following change was carried out on OPC ratio to determine the amount of OPC required to achieve the optimal phosphate removal. Two mixtures were prepared at water ratio $35 \%$ and OPC ratio at $2.5 \%$ and $10 \%$ from the dry weight of the limestone, respectively. The finding of both mixtures was compared with the first mixture (5\% OPC ratio) as shown in Figure 6. The experimental results introduced the OPC at $5 \%$ as the preferable ratio to maintain the phosphate removal and the bonding strength of mixed materials.

FBA is the main material for coating process. The optimum amount of FBA is determined in corresponding to the OPC ratio because the reaction between them generates the final form and properties for the new filter media. Previously, the optimum OPC ratio already determined at FBA ratio 50\% from the dry weight of the limestone. It is observed the media crushing to obtain the filter media as particles lead to lose an amount of the mixture of FBA and OPC. Therefore, FBA ratio was investigated at under $50 \%$ to reduce the loss of FBA. Figure 7 shows the filter media at FBA ratio $40 \%$ tend to be efficient in same level when the FBA ratio $50 \%$, while when reduced the $\mathrm{FBA}$ ratio to $30 \%$ the phosphate removal efficiency was decreased. According to the experimental results utilizing FBA ratio at $40 \%$ maintain the phosphate removal efficiency and reduced the quantity of FBA which applied in coating process.

According to the construction industry, the OPC requires 28 days to cure and reach $100 \%$ of its strength [28]. Therefore, all previous tests applied at 28 days to cure the mixtures. Study the influence of curing time on the new filter media helps to determine the actual required preparation time. The filter media at curing time 7 days presented a low phosphate removal efficiency compared to filter media at 14 and 28 days as shown in Figure 8. While, removal efficiency at 14

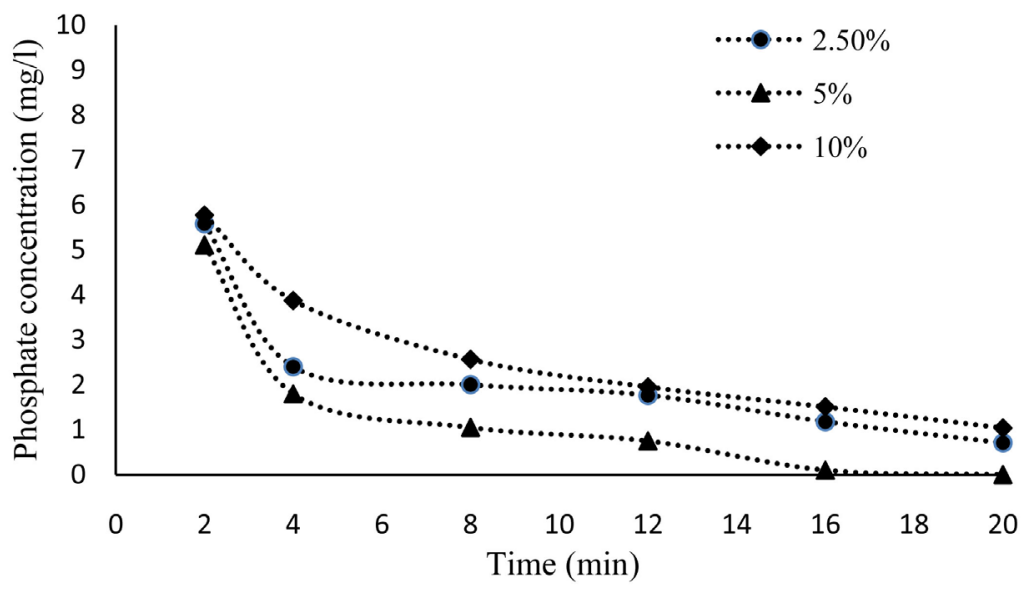

Figure 6. Effect of OPC ratio on the removal of phosphate. 


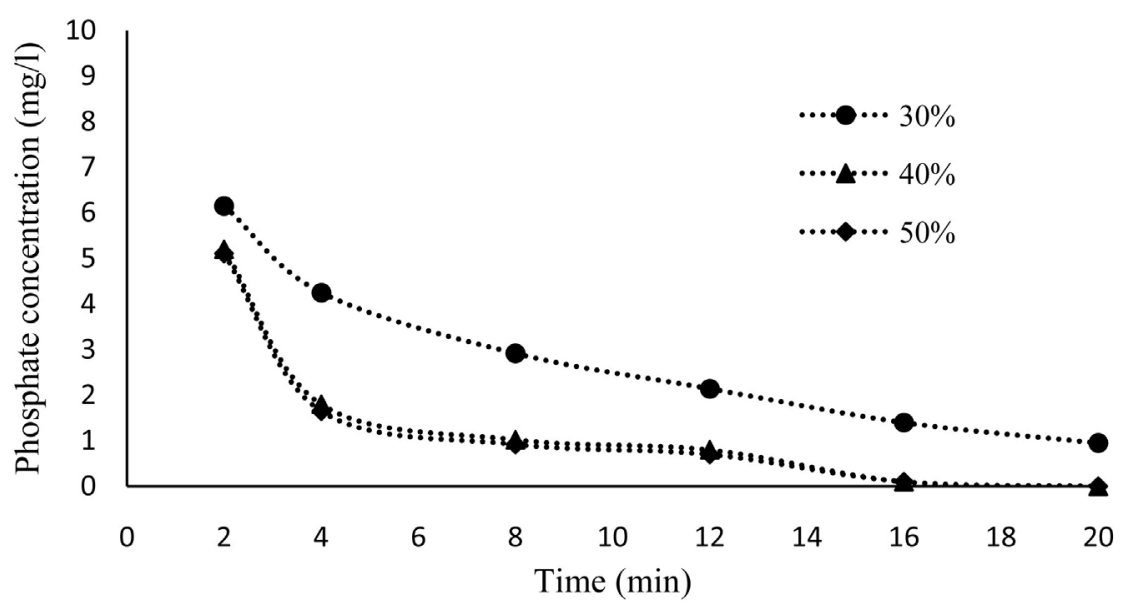

Figure 7. Effect of FBA dosage on the removal of phosphate.

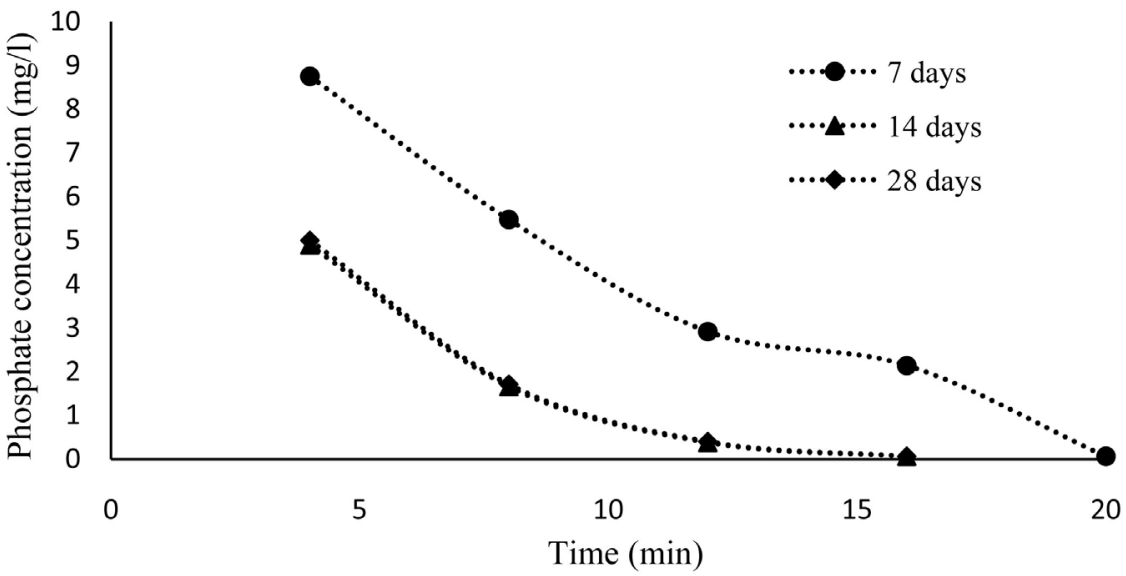

Figure 8. Effect of curing time on the removal of phosphate.

and 28 days looks approximately the same. According to the results, the portion of OPC that added to the mixtures recommended to cured for a minimum period of 14 days to achieve the adequate reaction between the mixed materials.

\subsection{Lifetime of LFBA}

A mass of $1500 \mathrm{~g}$ from the LFBA was packed in the upflow filter to investigate the phosphate sorption rate. It is calculated as the difference between influent and effluent concentrations for samples collected at the same time. The sorption of $\mathrm{P}$ was calculated using the following mass balance equation:

$$
q e=(C i-C e) V / m
$$

where $C i$ and $C e$ are initial $\mathrm{P}$ and effluent concentration $(\mathrm{mg} / \mathrm{l})$, respectively and $V(\mathrm{l})$ is the volume of phosphate aqueous solution treated during the experiment and $\mathrm{m}$ the mass $(\mathrm{kg})$ of the filter material. The influent pumped at flow rate 1 $1 / \mathrm{min}$ with volume 81 and concentration $10 \mathrm{mg} \mathrm{P} / \mathrm{l}$. According to the equation 1 , the phosphate sorption rate is $0.053 \mathrm{mg} \mathrm{P} / \mathrm{g}$ material for each $8 \mathrm{l}$ of phosphate solution reached the required effluent limit of $0.1 \mathrm{mg} \mathrm{P} / \mathrm{l}$. Along the term of the 
experiment, that all runs achieved the required phosphate limit but it is observed the removal time was increased as shown in Figure 9.

It is noticeable for the first runs (from 1 to 4 ) that the LFBA achieved the permissible phosphate limit after just two cycles. As a results of saturation of some positions onto the LFBA surface the rest of runs need more than two cycles to achieve the required phosphate removal. Furthermore, the number of cycles increased rapidly when goes further with this experiment. For instance, the LFBA need 2 and 2.5 cycles to control the phosphate concentration for the runs ( 1 to 4 ) and (5 to 8 ), respectively. While, it need to pump 18 cycles after 22 runs. It is true that the experiment showed that the LFBA still active to retain the phosphate. However, the decision to discontinue the experiment had been made because the treatment time became long.

\subsection{LFBA Activation}

LFBA presented high capacity for phosphate sorption but it is required to maintain its practicality by reduce the removal time. The phosphate sorption by metal oxides such as $\mathrm{Al} / \mathrm{Fe}$ decreases if the $\mathrm{pH}$ of the influent increased and desorption of the previous adsorbed phosphate ions. Activation experiments were conducted by washing the filter media with $0.1 \mathrm{M} \mathrm{NaOH}$ solution for $15 \mathrm{~min}$, the solution $\mathrm{pH}$ was increased to 9 by adding $\mathrm{NaOH}$. For economic reasons the concentration of $0.1 \mathrm{M} \mathrm{NaOH}$ solution was selected. Additionally, the washing time selected randomly. The LFBA sample that used to investigate it is lifetime was used to check the possibility of LFBA activation. It is noticeable in Figure 10 that the LFBA achieved complete phosphate removal after washing process in 30 min. This outcome had been compared with the findings of the experiment of LFBA lifetime as showed in Figure 10. There is significant improvement in capability of phosphate removal after washing process in comparison with the results of the last run before washing the LFBA. The LFBA required $144 \mathrm{~min}$ to obtain influent at the permissible limit of phosphate. While, LFBA after washing

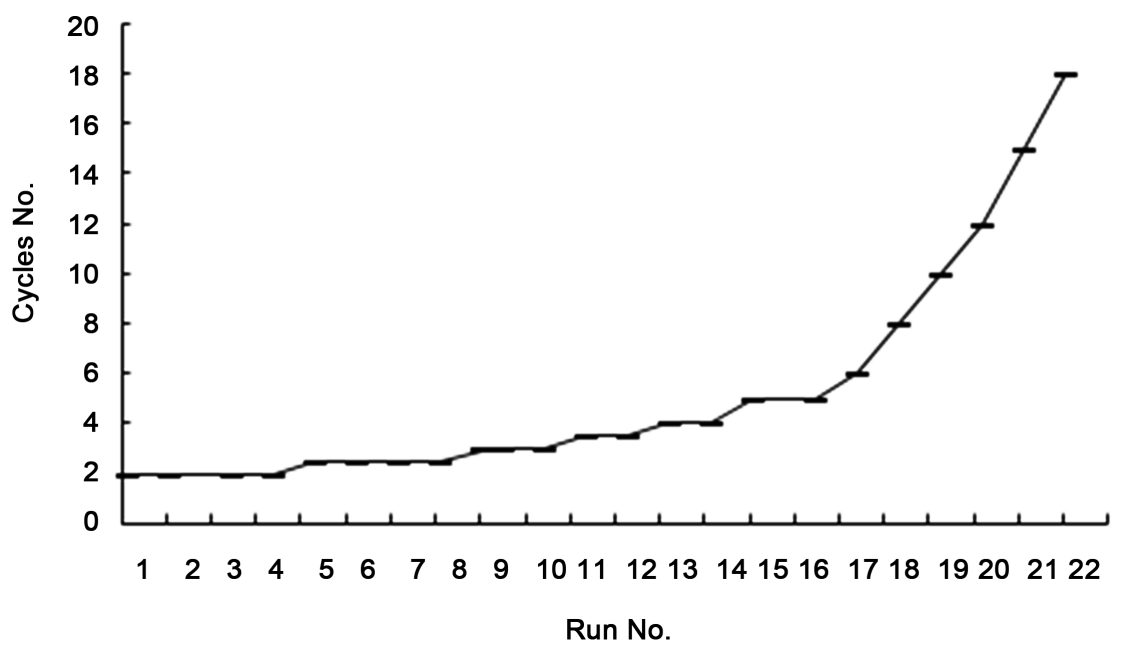

Figure 9. Saturation of filter media over the operating sessions. 


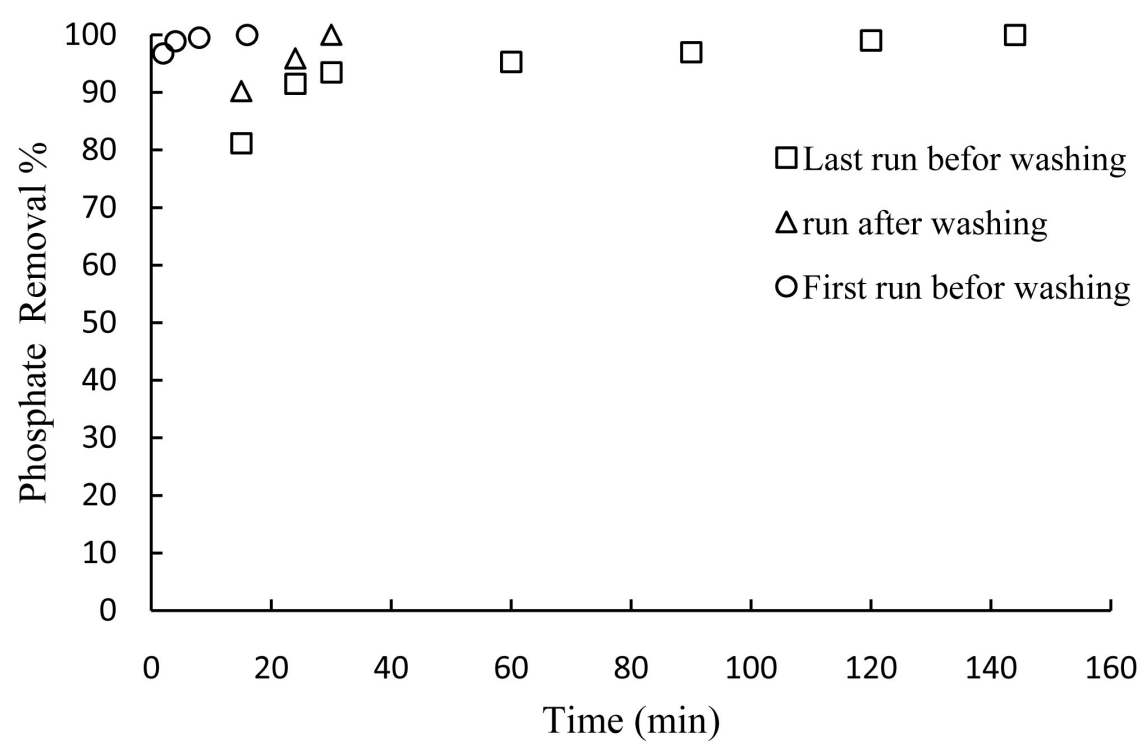

Figure 10. Phosphate removal efficiency after washing process.

introduced outstanding performance when achieved the same result in $114 \mathrm{~min}$ less. On the other hand, the efficiency of LFBA after washing was lower than the efficiency of LFBA for the first run; even it is lower than the first 12 runs. This indicates that the washing solution didn't detach all the adsorbed phosphate ions and some places onto the LFBA surface still saturated with phosphate.

Many advantages can gain as a result of filter media activation. Firstly, increases the filter lifetime. Secondly, transfer the pollutant (phosphate) from huge quantity (the total pumped phosphate solution was $176 \mathrm{l}$ ) to small controlled quantity (washing solution was $8 \mathrm{l}$ ). It is recommended; further study required for washing time, method and extracting the phosphate from washing solution.

\section{Discussion}

The presented work in this study is introduce a new approach regarding creating and developing the characteristics of the filter media which fit the economic and environmental requirements. The coating process was performed without need a source of energy such as heat in order to set the coating material over the surface of supporting material. Instead, a small portion of cementitious material such as OPC utilize as binder for binding the mixture materials. The cementitious materials merely need a water to activate them as binder. The outcomes of examination the efficiency of LFBA and SFBA leaded to select the limestone as support material in the filter mixture. There is a possible reason that made the limestone better option to be selected; it could be the FBA bond with limestone by OPC better than sand. One of major limestone component is calcium oxides which is able to produce cementitious compounds by hydration process that increases the stiffness of mixture.

Four factors have a key impact on the characteristics of the produced filter media; quantity of coating dosage, OPC ratio, water ratio and curing time. At 
the beginning, the mixture ratios were determined depending on previous review and laboratory judgment. Afterward an optimization process was conducted to determine the optimal mixture percentages, which achieved best phosphate removal. The sequence of factors examination was considered according to the order of the factors in the process of LFBA formation. These factors represent the cornerstone of formation of the LFBA. Therefore, optimizing their quantities is essential according to several considerations. Increase the OPC amount in the mixture will positively affect the strength of the materials' bonding. On the other hand, it negatively affects the chemical composition of new filter media. Especially, the availability of $\mathrm{Al}_{2} \mathrm{O}_{3}$ and $\mathrm{Fe}_{2} \mathrm{O}_{3}$, which are responsible for phosphate capture from the influent. The presence of pozzolanic material such as FBA caused a significant hydration for OPC. The water ratio is extremely sensitive for additives' reaction. Thus, the low added water quantity negatively affects the formation of the final product characteristics. While, if water quantity exceeds the required value, a segregation of material occurs and this will lead to an influence on the strength of bonding between the materials. During the filter media preparation, the unbound FBA is lost as a result of crushing media to obtain the filter media as particles. Therefore, determining the required FBA amount is important in terms of reducing the loss of FBA. Controlling the rate of moisture loss during the OPC hydration is very necessary. In order to obtain the required strength which achieves the binding between materials of the mixture.

The process of washing the LFBA by $0.1 \mathrm{M} \mathrm{NaOH}$ solution revealed significant result regard the possibility of regeneration the efficiency of LFBA to remove the phosphate. It is true the result looks promising. However, the current applied washing method required further study because it is suggested specific aspects and these aspects need to study deeper such as washing time, concentration of the solution and the washing methods.

A discussion has been conducted about the related previous works of which we are aware, which have focused on the issue of phosphate removal via active materials. Also, the performance of LFBA was compared to these other works. This discussion has focused on the recent works to ensure comparison that is more reliable. It is difficult to obtain a comparison without drawbacks because some researchers used different parameters from our study. LFBA was tested according to column experiments, many researchers studied the phosphate removal via batch experiments. Researches based on batch experiments have been excluded from comparison. While the filter materials, which were tested via column experiments have been used instead as shown in (Table 5).

The treatment method is not the only parameter that is considered to have a key impact on the phosphate retention capacity of filter materials. Many parameters have a significant influence on phosphate retention such as particle size of filter material, phosphate concentration in the influent and treatment time, which is related to flow rate of feed solution. High phosphate concentration may lead to a shortening of the required time to remove the phosphate. While, 
Table 5. LFBA and other filter materials used in flow column experiments.

\begin{tabular}{|c|c|c|c|c|c|c|c|c|}
\hline Material & Source & $\begin{array}{l}\text { Test } \\
\text { period } \\
\text { days }\end{array}$ & $\begin{array}{l}\text { P concentration } \\
\mathrm{mg} \cdot \mathrm{l}^{-1}\end{array}$ & $\begin{array}{l}\text { Particle } \\
\text { size } \mathrm{mm}\end{array}$ & $\begin{array}{l}\text { Loading } \\
\text { rate } \\
1 \cdot \mathrm{d}^{-1} \cdot \mathrm{g}^{-1}\end{array}$ & $\begin{array}{c}\text { Volume } \\
\text { of material } \\
\mathrm{cm}^{3}\end{array}$ & $\begin{array}{l}\text { P retention } \\
\mathrm{mg} \cdot \mathrm{g}^{-1}\end{array}$ & Reference \\
\hline LFBA & $\begin{array}{l}\text { Warrington power station, } \\
\text { North West England }\end{array}$ & 0.127 & 10 & $0.9-2.3$ & 0.96 & 1021 & 1.22 & \\
\hline Filtralite $\mathrm{P}$ & Saint-Gobain, Norway & 229 & 4.9 & $0.5-4$ & 0.00048 & 18800 & 0.473 & [29] \\
\hline Shellsand & $\begin{array}{l}\text { Natural material produced from } \\
\text { shell, snail and alga, Norway }\end{array}$ & 303 & 10 & $3-7$ & 0.00027 & 18300 & 0.497 & [29] \\
\hline $\begin{array}{l}\text { Iron-coated } \\
\quad \text { sand }\end{array}$ & $\begin{array}{l}\text { Someren, water treatment } \\
\text { plant, Netherlands }\end{array}$ & 238 & 3.95 & $<2$ & 0.0039 & n.a & n.a & [30] \\
\hline $\begin{array}{l}\text { Electric } \\
\text { furnace slag }\end{array}$ & Steel mill Ft. smith, AR, USA & 0.2 & $0.5-15$ & $6.35-11$ & $0.29-4.6$ & 1.1 & 1.3 & [31] \\
\hline
\end{tabular}

increasing the influent flow rate may decrease the phosphate uptake due to reducing the contact chance. On the other hand, small particle size of filter material offers a large surface area that increases the chance of contact between the feed solution and filter material. Based on these considerations, specific works have been selected to provide a more realistic insight into the efficiency of LFBA in comparison with related works. As listed in Table 5, some filter material has been selected to compare their outcomes with LFBA where they have somewhat similar parameters.

It is observed that filter materials such as Filtralite $\mathrm{P}$ and Shellsand required test periods of 229 and 303 days at loading rate at 0.00048 and $0.00027 \mathrm{l} \cdot \mathrm{d}^{-1} \cdot \mathrm{g}^{-1}$, respectively; to reach the saturation point. In contrast, the test period of LFBA is very short in comparison with Filtralite $\mathrm{P}$ and Shellsand; it was 0.127 days. While the loading rate is larger than their loading rates; it was $0.96 \mathrm{l} \cdot \mathrm{d}^{-1} \cdot \mathrm{g}^{-1}$. As illustrated above the test period is related to the loading rate of feed solution, long contact time and low influent loading rate leads to higher phosphate retention. However, the LFBA retains phosphate much better than Filtralite P and Shellsand. Although the LFBA did not reach the saturation point at these parameters the phosphate retention was $1.22 \mathrm{mg} \cdot \mathrm{g}^{-1}$. While, phosphate retention for Filtralite $\mathrm{P}$ and Shellsand was 0.473 and $0.497 \mathrm{mg} \cdot \mathrm{g}^{-1}$, respectively.

Chardon et al. [29] describe the phosphate removal via Iron-coated sand. It is a good opportunity to compare the phosphate uptake by LFBA with a coated filter material. The parameters of Iron-coated sand are somewhat similar to the parameters of Filtralite $\mathrm{P}$ and Shellsand as shown in Table 5 Chardon et al. [29] did not mention the phosphate retention by Iron-coated sand; but he states that the final concentration of effluent is $90 \%$ less than the concentration of influent. Based on operating conditions and phosphate removal percentage of Iron-coated sand, the LFBA also showed better characteristics in terms of phosphate retention.

Penn and McGrath [30] estimate the phosphate retention capacity of electric furnace slag. The outcomes indicate an outstanding performance by electric furnace slag to remove the phosphate. Therefore, it looks a promising material to 
act as filter material for retaining the phosphate. Electric furnace slag achieved phosphate retention $1.3 \mathrm{mg} \mathrm{g}-1$ during the test period 0.2 days. However, Penn and McGrath [30] indicate that electric furnace slag no longer retains phosphate after 0.2 days. Hence, electric furnace slag is saturated quickly, whereas LFBA is unsaturated at this point.

According to the findings of several researchers [31] [32] phosphate removal varies depending on many parameters which have an influence on performance of filter material such as phosphate concentration, loading rate and quantity of packed material. However, these parameters do not have an influence on all materials performance in the same manner and same magnitude as illustrated above in comparison with LFBA with other materials in Table 5. This leads the researcher to believe that chemical composition and physical characteristics play the key role in the process of phosphate removal via the PSMs. Specifically, LFBA results from the process of developing the physical and chemical characteristics that help to obtain an efficient material to act as phosphate sorption media in upflow system.

\section{Conclusion}

New filter media was created for phosphate removal and a comprehensive study was applied to investigate its eligibility as a sustainable solution for eutrophication problem. Limestone had better performance compared with sand to act as supporting material for filter media. The mixture characteristics are strongly depending on the type and amount of coating material, binder material, the water content, and curing time. According to the XRF analysis, the FBA contains a reasonable amount of $\mathrm{Al}$ and $\mathrm{Fe}$ oxides that help to capture the phosphate ions from the influent. Optimization process has been performed to determine the better mixture that introduced as an efficient filter media for phosphate removal. Optimization study included the factors which have influence on the mixture characteristics. The high capacity of LFBA for phosphate retains the possibility of regenerating it which makes it an attractive wastewater treatment method and consistent with sustainability approach.

\section{Acknowledgements}

The authors are grateful to the Dave Unsworth, the team leader of Fuel \& By-Product Logistics in Fiddlers Ferry Power Station for providing the furnace bottom ash used in this work. In addition, the authors would like to thank Omya UK Ltd for supplying the limestone. Especial thanks for the technical team of the labs of Henry Cotton in the Liverpool John Moores University for their assistance in construction of the filter rigs, especially, Mr. Feegan M.

\section{Conflicts of Interest}

The authors declare no conflicts of interest regarding the publication of this paper. 


\section{References}

[1] Mor, S., Chhoden, K. and Ravindra, K. (2016) Application of Agro-Waste Rice Husk Ash for the Removal of Phosphate from the Wastewater. Journal of Cleaner Production, 129, 673-680. https://doi.org/10.1016/j.jclepro.2016.03.088

[2] Peltzer, P.M., Lajmanovich, R.C., Sanchez-Hernandez, J.C., Cabagna, M.C., Attademo, A.M. and Basso, A. (2008) Effects of Agricultural Pond Eutrophication on Survival and Health Status of Scinax nasicus Tadpoles. Ecotoxicology and Environmental Safety, 70, 185-197. https://doi.org/10.1016/j.ecoenv.2007.06.005

[3] Hussain, S., Aziz, H.A., Isa, M.H., Ahmad, A., Van Leeuwen, J., Zou, L. and Umar, M. (2011) Orthophosphate Removal from Domestic Wastewater Using Limestone and Granular Activated Carbon. Desalination, 271, 265-272. https://doi.org/10.1016/j.desal.2010.12.046

[4] Yeoman, S., Stephenson, T., Lester, J.N. and Perry, R. (1988) The Removal of Phosphorus during Wastewater Treatment: A Review. Environmental Pollution, 49, 183-233. https://doi.org/10.1016/0269-7491(88)90209-6

[5] Huang, X., Liao, X. and Shi, B. (2009) Adsorption Removal of Phosphate in Industrial Waste-Water by Using Metal-Loaded Skin Split Waste. Journal of Hazardous Material, 166, 1261-1265. https://doi.org/10.1016/j.jhazmat.2008.12.045

[6] Morse, G.K., Brett, S.W., Guy, J.A. and Lester, J.N. (1998) Review: Phosphorus Removaland Recovery Technologies. Science of the Total Environment, 212, 69-81. https://doi.org/10.1016/S0048-9697(97)00332-X

[7] Liopez, E., Soto, B. and Arias, M. (1998) Adsorbent Properties of Red Mud and Its Use for Wastewater Treatment. Water Research, 32, 1314-1322. https://doi.org/10.1016/S0043-1354(97)00326-6

[8] Pradhan, J., Das, J. and Das, S.N. (1998) Adsorption of Phosphate from Aqueous Solution Using Activated Red Mud. Journal of Colloid and Interface Science, 204, 169-172. https://doi.org/10.1006/jcis.1998.5594

[9] Kandah, M.L. (2004) Zinc and Cadmium Adsorption Low-Grade Phosphate. Separation and Purification Technology, 35, 61-70. https://doi.org/10.1016/S1383-5866(03)00131-X

[10] Tillman, F.D., Bartelt-Hunt, S.L. and Craver, V.A. (2005) Relative Metal Ion Sorption on Natural and Engineered Sorbents: Batch and Column Studies. Environmental Engineering Science, 22, 400-409. https://doi.org/10.1089/ees.2005.22.400

[11] Osorio, F. and Hontoria, E. (2002) Wastewater Treatment with a Double-Layer Submerged Biological Aerated Filter, Using Waste Materials as Biofilm Support. Journal of Environmental Management, 65, 79-84. https://doi.org/10.1006/jema.2001.0530

[12] Yu, Y., Feng, Y., Qiu, L., Han, W. and Guan, L. (2008) Effect of Grain-Slag Media for the Treatment of Wastewater in a Biological Aerated Filter. Bioresource Technology, 99, 4120-4123. https://doi.org/10.1016/j.biortech.2007.09.001

[13] Hjelmar, O., Johnson, A. and Comans, R. (2010) Incineration: Solid Residues. In: Christensen, T.H., Ed., Solid Waste Technology and Management, John Wiley \& Sons, Ltd., Chichester, Chapter 8.4. https://doi.org/10.1002/9780470666883.ch29

[14] Lyngsie, G. (2013) Sorbents for Phosphate Removal from Agricultural Drainage Water. PhD Thesis, University of Copenhagen, Denmark.

[15] Benjamin, M., Sletten, R., Bailey, R. and Bennett, T. (1996) Sorption and Filtration of Metals Using Iron-Oxide-Coated Sand. Warter Resources, 30, 2609-2620. 
https://doi.org/10.1016/S0043-1354(96)00161-3

[16] Lu, J.B., Sun, L.P., Zhao, X.H., Lu, B., Li, Y.L. and Zhang, L. (2009) Removal of Phosphate from Aqueous Solution Using Iron-Oxide-Coated Sand Filter Media: Batch Studies. International Conference on Environmental Science and Information Application Technology, Wuhan, 4-5 July 2009, 639-644. https://doi.org/10.1109/ESIAT.2009.104

[17] Li, S., Cui, J., Zhang, Q., Fu, J., Lian, J. and Li, C. (2010) Performance of Blast Furnace Dust Clay Sodium Silicate Ceramic Particles (BCSCP) for Brewery Wastewater Treatment in a Biological Aerated Filter. Desalination, 258, 12-18. https://doi.org/10.1016/j.desal.2010.04.006

[18] Thomas, M. (2007) Optimizing the Use of Fly Ash in Concrete. Portland Cement Association, Skokie.

[19] Dunstan Jr. (2011) How Does Pozzolanic Reaction Make Concrete "Green"? World of Coal Ash (WOCA) Conference, Denver, 9-12 May 2011, 1-15.

[20] Jenkins, D., Ferguson, J. and Menar, A. (1971) Chemical Process for Phosphate Removal. Water Resources, 5, 369-389. https://doi.org/10.1016/0043-1354(71)90001-7

[21] Alzeyadi, A., Loffill, E. and Alkhaddar, R. (2015) Investigation into the Optimum Hydraulic Loading Rate for Selected Filter Media Packed in a Continuous Upflow Filter. International Journal of Civil, Envirnmental, Structural, Construction and Architectural Engineering, 9, 710-713.

[22] Alzeyadi, A., Loffill, E. and Alkhaddar, R. (2016) Study of Influent Transfer inside Filter Media Packed in a Laboratory Up-Flow Filtration Regime. The 2nd BUiD Annual Doctoral Research Conference, Dubai, 14-15 May 2016, 1-9.

[23] Loffill, E. (2011) The Optimisation of Nitrifying Continuous Up-Flow Filters for Tertiary Wastewater Treatment. PhD Thesis, Liverpool John Moores University, Liverpool.

[24] Gehrs, C.W., Shriner, D.S. and Herbes, S.E. (1979) Environmental Health and Safety Implications of Increased Coal Utilization, Chemistry of Coal Utilization. Chemistry of Coal Utilization, 2, 2194-2219.

[25] Mangialardi, T., Piga, L., Schena, G.P. and Sirini (1998) Characteristics of MSW Incinerator Ash for Use in Concrete. Environmental Engineering Science, 15, 291-297. https://doi.org/10.1089/ees.1998.15.291

[26] Gupta, G. and Torres, N. (1998) Use of Fly Ash in Reducing Toxicity of and Heavy Metals in Wastewater Effluent. Journal of Hazardous Material, 57, 243-248. https://doi.org/10.1016/S0304-3894(97)00093-9

[27] EPA. Table of Regulated Drinking Water Contaminants. https://www.epa.gov/ground-water-and-drinking-water/table-regulated-drinking-w ater-contaminants

[28] Barger, E. (2013) The 28-Day Myth. http://precast.org/2013/10/28-day-myth

[29] Ádám, K., Krogstad, T., Vråle, L., Søvik, A.K. and Jenssen, P.D. (2007) Phosphorus Retention in the Filter Materials Shellsand and Filtralite P-Batch and Column Experiment with P Solution and Secondary Wastewater. Ecological Engineering, 29, 200-208. https://doi.org/10.1016/j.ecoleng.2006.09.021

[30] Chardon, W.J., Groenenberg, J.E., Temminghoff, E.J. and Koopmans, G.F. (2012) Use of Reactive Materials to Bind Phosphorus. Journal of Environmental Quality, 41, 636-646. https://doi.org/10.2134/jeq2011.0055

[31] Penn, C.J. and McGrath, J.M. (2011) Predicting Phosphorus Sorption onto Steel 
Slag Using a Flow-Through Approach with Application to a Pilot Scale System. Journal of Water Resource and Protection, 3, 235-244.

https://doi.org/10.4236/jwarp.2011.34030

[32] Klimeski, A., Wim, J.C., Turtola, E. and Uusitalo, R. (2012) Potential and Limitations of Phosphate Retention Media in Water Protection: A Process-Based Review of Laboratory and Field-Scale Tests. Agricultural and Food Science, 21, 206-223. https://doi.org/10.23986/afsci.4806 